\title{
Integração de informação e reativação da memória: impacto positivo de uma intervenção cognitivo-motora em bebês
}

\author{
Information integration and memory reactivation: the positive effects of a cognitive-motor intervention \\ in babies
}

Carla Skilhan de Almeida ${ }^{1}$, Nadia Cristina Valentini $^{2}$

\section{RESUMO}

Objetivo: Investigar os efeitos de uma intervenção cognitivo-motora na integração de informação e reativação da memória de bebês.

Métodos: Participaram do estudo 40 bebês de seis a oito meses de idade, nascidos a termo e matriculados em creches, permanecendo nelas sete horas por dia com relação educador/bebê de 1/6, provenientes de famílias numerosas e de baixa renda que não participavam de programas interventivos. Uma intervenção cognitivo-motora foi propiciada ao Grupo Interventivo com atividades de perseguição visual, manipulação de brinquedo e controle postural. Para o Grupo Controle, nenhuma intervenção foi propiciada. As atividades da rotina da creche foram mantidas para os dois grupos. Três atividades de manipulação foram avaliadas no início do programa, um mês depois (retenção) e três dias após a retenção. Para a análise dos dados, foram utilizados o teste do qui-quadrado com correção de Yates, o teste exato de Fisher e o de Cochran.

Resultados: O Grupo Interventivo demonstrou desempenho significativamente superior ao Grupo Controle em evocar informações da memória na retenção e pós-retenção em duas atividades. Mudanças significativas e positivas também foram observadas para o Grupo Interventivo no fator tempo. Os bebês mais velhos do Grupo Interventivo demonstraram melhor capacidade de evocar informação em relação aos mais jovens. Essa tendência não foi observada para o Grupo Controle.
Conclusões: Para potencializar o desenvolvimento global de bebês, as intervenções deveriam ser organizadas implementando tarefas diversificadas com intervalos de aprendizagem apropriados, os quais levem em consideração a capacidade dos bebês de manterem a informação e integrarem essa informação a novos desafios.

Palavras-chave: fisioterapia; desenvolvimento infantil; memória.

\section{ABSTRACT}

Objective: To investigate the effects of a cognitive-motor intervention in the information integration and memory reactivation of babies.

Methods: The participants were 40 babies, aged between six to eight months, born full term, adapted to day care centers and staying there for seven hours per day. In the day care center, the ratio caregiver/baby was $1 / 6$. The patients belong to low income' large families and they did not participate in intervention programs. A cognitive-motor intervention was provided to the Intervention Group using visual tracking, toy manipulation and postural control activities. No intervention was provided to the Control Group. The day care routine activities were maintained for both groups. Three manipulation activities were assessed in the beginning of the program, after a month (retention) and three days after retention. Statistical analysis applied the chi-square with Yates correction, Fisher exact test and Cochran test.

Nadia Cristina Valentini

Rua Felizardo, 750 - Jardim Botânico

CEP 90690-200 - Porto Alegre/RS

E-mail: nadiacv@esef.ufrgs.br

Fonte de financiamento: Conselho Nacional de Desenvolvimento Científico e Tecnológico (CNPq); Edital Universal, processo 472378; Bolsa pelo Programa Institucional de Bolsas de Iniciação Científica (Pibic) do CNPq da UFRGS, projeto 6591; Bolsa Produtividade em Pesquisa, processo 307885.

Conflito de interesse: nada a declarar

Recebido em: 28/1/2009

Aprovado em: 31/8/2009 
Results: The Intervention Group showed a significantly superior performance when compared to the Control Group in the retrieval of memory information, both at retention and post-retention tests. Significant and positive changes were also observed for the Intervention Group in the time factor. The older babies in the Intervention Group showed a better capacity to evocate information compared to the youngest ones. This trend was not observed for the Control Group.

Conclusions: In order to nourish a baby's global development, interventions should be organized implementing tasks with diversity and appropriate learning intervals, which take into consideration the babies' capacity to maintain the information and to integrate them to new challenges.

Key-words: physical therapy; child development; memory.

\section{Introdução}

Nos primeiros anos de vida, uma maior plasticidade cerebral possibilita a otimização do desenvolvimento social, motor e cognitivo, tornando o indivíduo mais sensível às oportunidades de aprendizagem. A criança desenvolve suas habilidades por meio das estruturas do seu corpo, as quais se auto-organizam em um processo dinâmico de cooperação entre múltiplos subsistemas (muscular, nervoso, glandular, motivacional e perceptivo, entre outros) associadas a objetivos que a criança tem no seu dia-a-dia (tarefas específicas), influenciadas pelo meio (casa, escola) em que a criança está inserida $^{(1,2)}$.

Um ambiente rico em experiências sensoriais (propiciadas por familiares, educadores e terapeutas) é vital para o desenvolvimento infantil ${ }^{(3)}$. Entretanto, a exposição do bebê a experiências que objetivam a mudança de comportamento decorrente dessas experiências (aprendizagem) ${ }^{(4)}$ deve considerar a habilidade deste em recordar ou reconhecer experiências anteriores (memória) ${ }^{(5,6)}$, integrar informações na memória ${ }^{(6,7)}$ e reativar a memória, processo que ocorre quando o encéfalo recria, em instantes, memórias que levaram horas para serem formadas. Portanto, as experiências individuais podem maximizar o aprendizado e a sua retenção. Quando ocorre a exposição do bebê a uma nova experiência, na prática interventiva ou no convívio familiar, o profissional e os cuidadores devem estar cientes de que o período para a aprendizagem pode ser limitado ${ }^{(4,7)}$.

Um novo paradigma para a memória dos bebês tem sido proposto. Os autores chamam esta proposta de "Janelas do
Tempo"(4,7). Ao deparar-se com uma determinada situação, o bebê integra esta informação na memória, o que se chama de "abertura da janela"(7-9). Essa "janela" se fecha caso experiências semelhantes não sejam vivenciadas. Entretanto, se o evento inicial ou semelhante for propiciado ao bebê de tempos em tempos, ocorre a reativação da memória do bebê, retardando o fechamento da "Janela do Tempo"( 4,7$)$. Sempre que experiências são integradas na memória, elas predispõem o indivíduo ao aprendizado. Se uma tarefa semelhante à inicial for realizada próximo ao fechamento da janela, este evento serve como uma "dica" e auxilia o bebê a recuperar a memória para aquela tarefa; a informação se mantém na memória por mais tempo e novos acontecimentos se integram com as informações iniciais ${ }^{(4,9)}$. A abertura da "Janela", as vivência posteriores e a consequente integração de informações são fundamentais para o desenvolvimento cognitivo do indivíduo ${ }^{(4)}$. Entender esse processo é fator determinante na efetividade de uma intervenção cognitivo-motora. Programas interventivos são necessários, principalmente para crianças que possuem poucas oportunidades de vivenciar um contexto variado e desafiador de suas potencialidades ${ }^{(8,10-13)}$.

Assim, este estudo teve como objetivos investigar os efeitos de uma intervenção cognitivo-motora na integração de informação e reativação da memória de bebês no terceiro trimestre de vida e a integração de informação e reativação da memória nas diferentes idades (seis a nove meses). As seguintes hipóteses foram estabelecidas: bebês do Grupo Interventivo (GI) demonstrariam desempenho significativamente superior no teste de retenção ("dica”), quando comparados com os bebês do Grupo Controle (GC); bebês do GI e do GC que não reconhecessem as tarefas na retenção demonstrariam capacidade de integrar informações e reativar a memória na pós-retenção; e os bebês mais velhos (de oito a nove meses) do GI e do GC demonstrariam capacidade de integração de informação e reativação da memória significativamente superior aos bebês mais novos (seis a sete meses).

\section{Métodos}

Estudo quase-experimental, no qual o contexto de aprendizagem interventivo foi ajustado à realidade das creches e ameaças à validade interna foram controladas. $\mathrm{O}$ estudo possui também um caráter transversal e prospectivo, neste participaram dois grupos de bebês nascidos a termo, aleatoriamente distribuídos (caso-controle) em GI ( $n=20)$ e GC $(n=20)$, com idades entre seis e oito meses, que frequentavam creches para populações de baixa renda. Dez creches sugeridas 
pela Secretaria da Educação de Porto Alegre, cujas famílias foram avaliadas pelos pesquisadores entre as classes $\mathrm{C}$ e $\mathrm{D}$, conforme Critério da Classificação Econômica do Brasil ${ }^{(14)}$, abrigavam bebês que cumpriam os critérios de inclusão. Os seguintes critérios foram considerados para a participação dos bebês: estavam adaptados à creche por mais de duas semanas $^{(15)}$, permaneciam na creche sete horas por dia, não participavam de programa de intervenção e possuíam relação educador/bebê de um para seis.

As características do contexto dos bebês quanto às condições econômicas das famílias, escolaridade dos pais e oportunidades de estimulação diárias nas escolas estão demonstradas na Tabela 1. No início do estudo, o GI apresentou média de

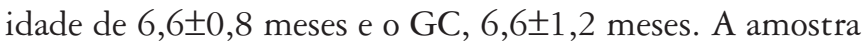
era composta por 12 meninas no GI (60\%) e 11 no GC (55\%). Nenhum bebê sofreu alguma intercorrência de saúde no decorrer do estudo que levasse à ausência prolongada ou a internações.

Este estudo foi aprovado pelo Comitê de Ética e Pesquisa da Universidade Federal do Rio Grande do Sul e os princípios éticos foram respeitados, baseados na resolução 196/96 do Conselho Nacional de Saúde do Ministério da Saúde. O termo de consentimento livre e esclarecido foi obtido para cada participante.

O GI participou do programa de intervenção cognitivomotora individualizado, três vezes por semana (dez sessões de 15 minutos cada), por aproximadamente um mês, baseado em estudos prévios ${ }^{(4,7,8,10,11)}$. O programa de intervenção cognitivo-motora tinha atividades de perseguição visual ${ }^{(8,16,17)}$, manipulação de diferente objetos e atividades de controle postural $^{(8,16)}$. Todos os bebês foram avaliados previamente e mostravam desenvolvimento normal, sendo esse semelhante entre os grupos $(p=0,74)$, conforme a Escala do Desenvolvimento do Comportamento da Criança no Primeiro Ano de $V_{i d a}{ }^{(12)}$. Esta escala permite uma avaliação global da criança normatizada por gênero, com escore total diferenciado para meninos e meninas, controlando as possíveis influências de gênero. Na perseguição visual, o brinquedo a ser observado era colocado em frente ao bebê a uma distância de $45 \mathrm{~cm}^{(8)}$ e movido, pelo examinador, em direções aleatórias por três minutos $^{(8)}$. Na manipulação eram realizadas tarefas uni e bimanuais (pinça, encaixe, puxar, empurrar, tatear e balançar) ${ }^{(8,16,18)}$. Nos cinco minutos finais, atividades de controle postural $^{(19)}$ foram implementadas. Todas as atividades foram realizadas com a interação do examinador. Para cada sessão interventiva, novas tarefas eram propostas garantindo a diversificação das atividades e a otimização de desafios ${ }^{(11)}$.

O impacto da intervenção cognitivo-motora na integração de informação e reativação de memória de bebês foi avaliado por meio de três testes de manipulação, baseado em estudo prévio de Fagard e Péze ${ }^{(16)}$, os quais envolvem subsistemas perceptivo e cognitivo expresso por meio de ação motora. Os testes foram filmados para posterior avaliação: a retirada de um brinquedo inserido em uma caixa (Figura 1), a retirada da cobertura de um brinquedo escondido (Figura 2) e a retirada de quatro pequenos brinquedos de um tubo de papelão, os quais estavam unidos por um barbante (Figura 3). As três tarefas de manipulação serviram exclusivamente aos procedimentos de coleta de dados, não sendo utilizadas ao longo da intervenção.

As tarefas foram apresentadas para os bebês (GI e GC) no início do programa, na retenção como "dica" (ao término

Tabela 1 - Comparações entre os Grupos Intervenção e Controle no que se refere ao contexto ambiental

\begin{tabular}{|c|c|c|c|}
\hline & \multicolumn{2}{|c|}{ Grupo } & \multirow[b]{2}{*}{ Valor de $p$} \\
\hline & $\begin{array}{c}\text { Intervenção } \\
n=20\end{array}$ & $\begin{array}{c}\text { Controle } \\
n=20\end{array}$ & \\
\hline \multicolumn{4}{|l|}{ Características econômicas das famílias } \\
\hline Classe C & $10(50 \%)$ & $8(40 \%)$ & 0,75 \\
\hline Classe D & $10(50 \%)$ & $12(60 \%)$ & \\
\hline \multicolumn{4}{|l|}{ Características das famílias } \\
\hline Família numerosa (mais de dois irmãos) & $11(55 \%)$ & $13(65 \%)$ & 0,75 \\
\hline Escolaridade dos pais & & & \\
\hline Primeiro grau completo ou menos & $15(75 \%)$ & $17(85 \%)$ & 0,69 \\
\hline Segundo grau completo ou mais & $5(25 \%)$ & $3(15 \%)$ & \\
\hline \multicolumn{4}{|l|}{ Oportunidade de estimulação diária na escola } \\
\hline $\begin{array}{l}\text { Escolas com atividades/brincadeiras (no } \\
\text { chão, no tatame, diariamente) }\end{array}$ & $8(40 \%)$ & $6(30 \%)$ & 0,74 \\
\hline $\begin{array}{l}\text { Escolas sem atividades/brincadeiras } \\
\text { (permanência em berços e bebê conforto) }\end{array}$ & $12(60 \%)$ & $14(70 \%)$ & \\
\hline
\end{tabular}




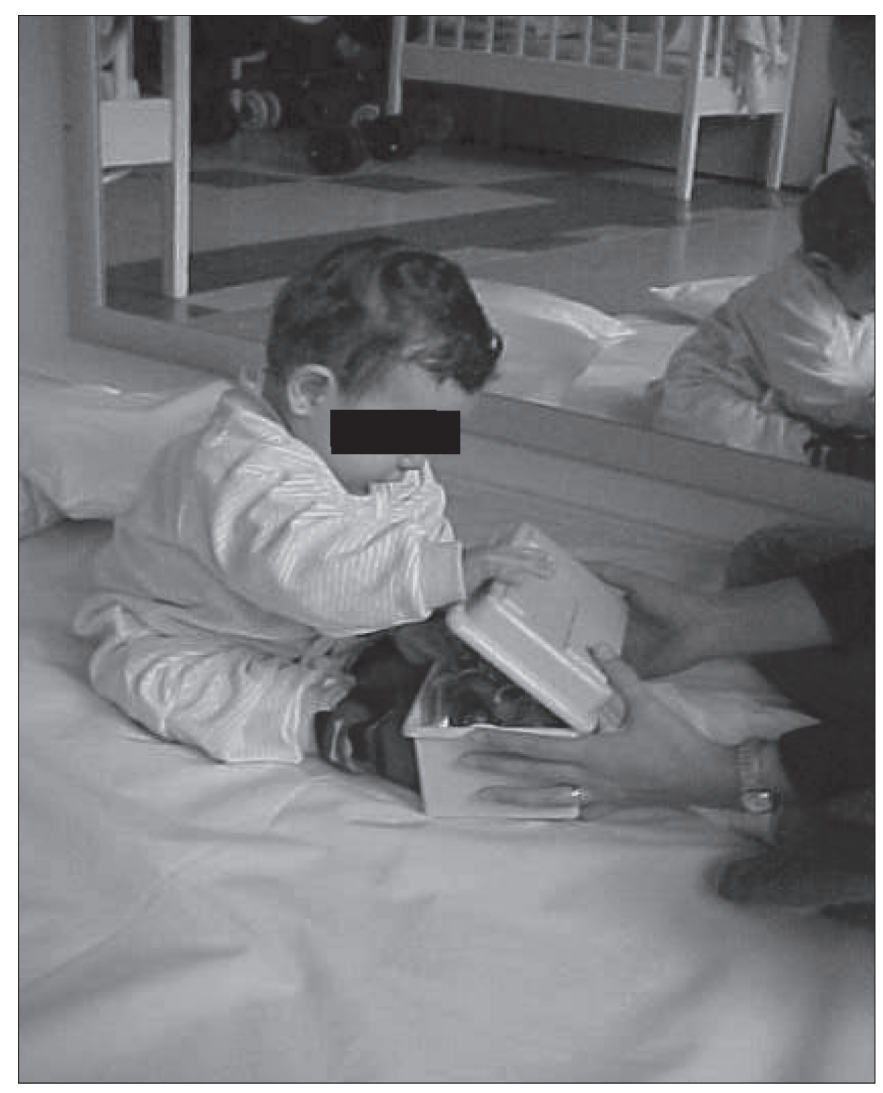

Figura 1 - Retirada de um brinquedo inserido em uma caixa.

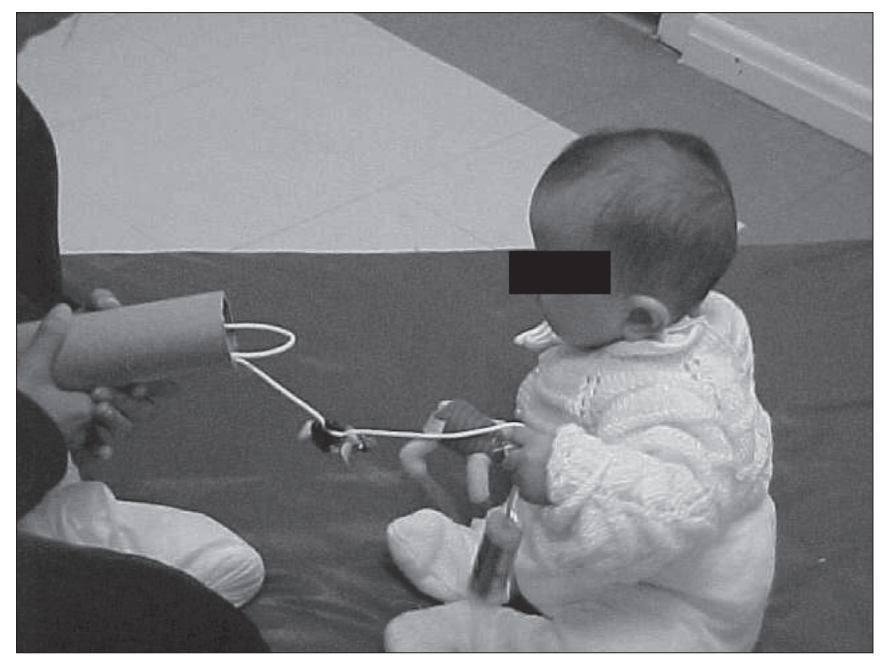

Figura 3 - Retirada de quatro pequenos brinquedos de um tubo de papelão unidos por um barbante.

do programa) e três dias após a retenção (pós-retenção). O teste de retenção foi o critério que indicou se o bebê lembrou ou não das tarefas do teste inicial. Na primeira avaliação (antes de iniciar o programa interventivo), as tarefas foram propiciadas ao bebe até que o mesmo as realizasse com sucesso ${ }^{(4,7)}$. Dados dicotômicos, "sim" e "não", foram

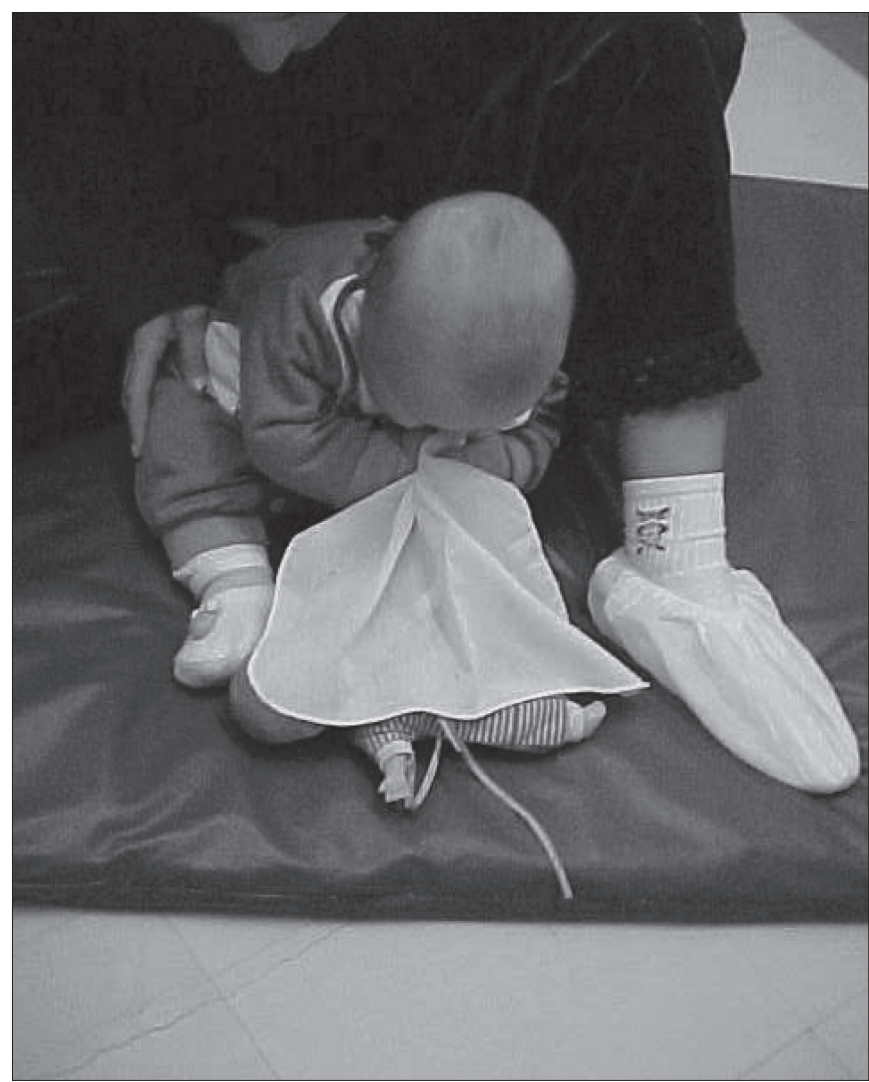

Figura 2 - Retirada da cobertura de um brinquedo escondido.

utilizados. Caso o bebê não executasse a tarefa no primeiro contato (avaliação inicial), várias oportunidades de repetir a tarefa até a execução com sucesso desta eram propiciadas ao bebê, embora ele recebesse o "não" por não conseguir realizá-la inicialmente. Após a execução com sucesso, os bebês permaneciam por três minutos realizando a tarefa ativamente, sem auxílio, para a mesma ser aprendida ${ }^{(7)}$. As tarefas foram repetidas de forma ativa na retenção e pós-retenção, porém em nenhum momento do programa interventivo. $\mathrm{Na}$ atividade da retirada de um brinquedo inserido em uma caixa, o sucesso era caracterizado sempre que o bebê abria a caixa e retirava dela um objeto; o nãosucesso era caracterizado por ignorar o objeto e (ou somente) manipular a caixa sem evidenciar iniciativa de abri-la. Na atividade de retirar a cobertura de um brinquedo escondido, o sucesso se caracterizava pela procura do brinquedo sob a cobertura; o não-sucesso se caracterizava por não descobrir o brinquedo. $\mathrm{Na}$ atividade de retirar quatro pequenos brinquedos de um tubo de papelão unidos por um barbante, o sucesso era obtido com a retirada dos quatro brinquedos do tubo de uma só vez; e o não-sucesso, pela não-retirada do brinquedo ou pela retirada de um a um, como se fosse a primeira vez que ele aparecia para o bebê. 
Dois examinadores (o pesquisador e um examinador cego e treinado que não participou do trabalho de intervenção) avaliaram o desempenho dos bebês nas tarefas manipulativas, utilizando as filmagens feitas em VHS. O índice de objetividade entre avaliadores foi analisado por meio do teste Kappa. No momento inicial da intervenção, retenção e pós-retenção, nas três tarefas houve um índice de concordância de $100 \%$ entre o pesquisador e o avaliador cego. A única exceção foi na tarefa de retirar o brinquedo da caixa, na retenção, com coeficiente Kappa de 0,75.

Os materiais utilizados foram: uma filmadora Sony $12 \mathrm{X} /$ Handycam, tatames, brinquedos coloridos com tamanhos e finalidades diferentes, caixa plástica com tampa $(10,4 \times 2,3 \mathrm{~cm})$, tubo de papelão enrijecido $(45 \mathrm{~cm}$ de comprimento e $5 \mathrm{~cm}$ de circunferência), pano para cobrir o brinquedo e fichas de avaliação.

Para os dados referentes à aprendizagem e reativação da memória do bebê, o teste do qui-quadrado com correção de Yates e/ou o teste exato de Fisher foram utilizados nas comparações dos grupos e entre os gêneros. O teste de Cochran foi utilizado para comparação intragrupos (inicial, retenção e pós-retenção). Aplicou-se o teste do qui-quadrado de McNemar para investigar em qual momento os bebês diferiram em seus desempenhos em diferentes idades, sempre que o teste de Cochran apresentasse diferenças significantes. Considerou-se significante $p<0,05$.

\section{Resultados}

Os dados evidenciaram semelhanças no desempenho em todas as atividades quanto ao gênero. Nas comparações de grupos, houve semelhanças nos três momentos avaliativos para a tarefa de retirar o brinquedo da caixa. Para a atividade de retirar o pano que esconde o brinquedo, os grupos eram inicialmente semelhantes, entretanto, no GI notou-se melhor desempenho na retenção e pós-retenção, o mesmo ocorreu para a atividade de tirar o brinquedo do tubo na avaliação pós-retenção. Especificamente, 18 bebês do GI reconheceram com sucesso essa tarefa manipulativa, enquanto que somente quatro bebês reativaram a memória na pós-retenção no GC (Tabela 2).

Houve modificações significantes e positivas no desempenho do GI da avaliação inicial para a retenção nas atividades de retirar o brinquedo da caixa $(p=0,03)$ e retirar o pano do brinquedo $(p=0,02)$, com manutenção do desempenho no período pós-retenção ( $p=1,00$ nas duas atividades). Para o GC, o desempenho foi semelhante entre o teste inicial e a retenção nas duas atividades $(p=0,06$ e $p=0,16$, respectivamente) e entre a retenção e o período pós-retenção $(p=0,22$ e $p=1,00$, respectivamente). Para a atividade de retirada de quatro pequenos brinquedos unidos por um barbante do tubo de papelão, os resultados estatísticos não evidenciaram mudanças significativas do início para a retenção, pois nenhum bebê reconheceu a tarefa tanto no GI $(p=1,00)$ como no GC $(p=1,00)$. Entretanto, da retenção para a pós-retenção, tanto o GI $(p<0,0001)$ como o GC $(p=0,018)$ apresentaram mudanças significativas e positivas no desempenho.

Nas comparações entre as idades, os resultados sugerem que os bebês mais velhos do GI (oito e nove meses) em relação aos mais jovens (seis e sete meses) demonstraram superioridade de desempenho na atividade de descobrir o brinquedo $(p=0,01)$ e retirar o brinquedo do tubo $(p=0,01)$, sem significância para a tarefa de retirar brinquedo da caixa $(p=0,09)$. Para o GC, os bebês de diferentes idades demonstraram desempenho semelhante nas três atividades ( $p=1,00 ; 0,64 \mathrm{e}$ 0,30 , respectivamente). Entre seis e nove meses, observou-se uma progressão com a idade, com um percentual mais elevado de bebês que conseguiam realizar a tarefa no GI. Essa situação não foi observada no GC (Tabela 3).

\section{Discussão}

Os resultados no fator tempo evidenciam que, no GI, um número significativo de bebês aprendeu a tarefa do teste inicial e a realizou com sucesso no teste de retenção, o que não foi observado para o GC. O sucesso para realizar a atividade de retirar o brinquedo inserido em uma caixa foi dependente da capacidade do bebê lembrar, na retenção, que dentro da caixa existia um brinquedo, uma vez que o mesmo já havia experimentado essa tarefa na avaliaçãa ${ }^{(8,16)}$. Tal aprendizagem foi facilitada pelo processo interventivo que, ao propiciar atividades desafiadoras, mesmo não semelhantes àquelas usadas nas avaliações, facilitou a integração de novas informações com o conhecimento prévio. Rovee-Collier ${ }^{(7)}$ relata que eventos particulares e diversos, quando relembrados continuamente, unem-se, acumulamse e codificam as informações por relativo período de tempo na memória.

Os resultados também sugerem que os bebês que não reconheceram a tarefa na retenção (tanto para o GI como para o GC) não obtiveram respostas na evocação da memória três dias depois, no período pós-retenção. Estudos prévios, embora não interventivos, em geral apresentam uma tendência diferenciada ${ }^{(7)}$, com participantes utilizando 
Tabela 2 - Comparações entre os Grupos Interventivo, Controle e Gênero nas três atividades manipulativas, frequência do sucesso ou não na atividade e nível de significância

\begin{tabular}{|c|c|c|c|c|c|}
\hline & \multicolumn{2}{|c|}{ Grupo Interventivo } & \multicolumn{2}{|c|}{ Grupo Controle } & \multirow{3}{*}{ Comparações } \\
\hline & Meninas & Meninos & Meninas & Meninos & \\
\hline & $n=12$ & $n=8$ & $n=11$ & $n=9$ & \\
\hline \multicolumn{6}{|c|}{ Retirar o brinquedo da caixa } \\
\hline \multicolumn{6}{|l|}{ Inicial } \\
\hline Sim & 2 & 1 & 1 & 0 & Grupos: $0,60^{*}$ \\
\hline Não & 10 & 7 & 10 & 9 & Gênero: $0,74^{*}$ \\
\hline \multicolumn{6}{|c|}{ Retenção } \\
\hline Sim & 4 & 5 & 3 & 3 & Grupos: $0,51^{* *}$ \\
\hline Não & 8 & 3 & 8 & 6 & Gênero: $0,90^{*}$ \\
\hline \multicolumn{6}{|c|}{ Pós-retenção } \\
\hline Sim & 4 & 5 & 6 & 5 & Grupos: $1,00^{* *}$ \\
\hline Não & 8 & 3 & 5 & 4 & Gênero: $0,80^{*}$ \\
\hline \multicolumn{6}{|c|}{ Retirar o pano do brinquedo } \\
\hline \multicolumn{6}{|l|}{ Inicial } \\
\hline Sim & 8 & 3 & 4 & 4 & Grupos: $0,53^{*}$ \\
\hline Não & 4 & 5 & 7 & 5 & Gênero: $0,60^{*}$ \\
\hline \multicolumn{6}{|c|}{ Retenção } \\
\hline Sim & 11 & 7 & 4 & 3 & Grupos: $0,01^{* *}$ \\
\hline Não & 1 & 1 & 7 & 6 & Gênero: $0,79^{*}$ \\
\hline \multicolumn{6}{|c|}{ Pós-retenção } \\
\hline Sim & 11 & 8 & 6 & 5 & Grupos: $0,01^{* *}$ \\
\hline Não & 1 & 0 & 5 & 4 & Gênero: $0,94^{*}$ \\
\hline \multicolumn{6}{|c|}{ Tirar o brinquedo do tubo } \\
\hline \multicolumn{6}{|l|}{ Inicial } \\
\hline Sim & 0 & 0 & 0 & 0 & Grupos: NA \\
\hline Não & 12 & 8 & 11 & 9 & Gênero: $0,75^{*}$ \\
\hline \multicolumn{6}{|c|}{ Retenção } \\
\hline Sim & 0 & 0 & 0 & 0 & Grupos: NA \\
\hline Não & 12 & 8 & 11 & 9 & Gênero: $0,83^{*}$ \\
\hline \multicolumn{6}{|c|}{ Pós-retenção } \\
\hline Sim & 11 & 7 & 2 & 2 & Grupos: $<0,001^{* *}$ \\
\hline Não & 1 & 1 & 9 & 7 & Gênero: $0,80^{*}$ \\
\hline
\end{tabular}

NA: não é possível aferir o valor de $p$.

Tabela 3 - Desempenho dos Grupos Intervenção e Controle nas diferentes idades, nas três atividades manipulativas

\begin{tabular}{lllccccc}
\hline & & \multicolumn{3}{c}{ Tarefas } \\
\cline { 3 - 7 } $\begin{array}{l}\text { Idade em } \\
\text { meses }\end{array}$ & Grupos & \multicolumn{2}{c}{ Caixa } & \multicolumn{2}{c}{ Descobrir o brinquedo } & \multicolumn{2}{c}{ Tubo } \\
\cline { 3 - 8 } & & $\begin{array}{c}\text { Sucesso } \\
(\%)\end{array}$ & $\begin{array}{c}\text { Não- } \\
\text { sucesso } \\
(\%)\end{array}$ & $\begin{array}{c}\text { Sucesso } \\
(\%)\end{array}$ & $\begin{array}{c}\text { Não- } \\
\text { sucesso } \\
(\%)\end{array}$ & $\begin{array}{c}\text { Sucesso } \\
(\%)\end{array}$ & $\begin{array}{c}\text { Não- } \\
\text { sucesso } \\
(\%)\end{array}$ \\
\hline 6 e 7 & Intervenção $(n=9)$ & $2(22)$ & $7(78)$ & $7(78)$ & $2(22)$ & $7(78)$ & $2(22)$ \\
& Controle $(n=9)$ & $3(33)$ & $6(67)$ & $2(22)$ & $7(78)$ & $3(33)$ & $6(67)$ \\
8 e 9 & Intervenção $(n=11)$ & $7(64)$ & $4(36)$ & $11(100)$ & 0 & $11(100)$ & 0 \\
& Controle $(n=11)$ & $4(36)$ & $7(64)$ & $4(36)$ & $7(6)$ & $1(9)$ & $10(91)$ \\
\hline
\end{tabular}


a própria avaliação na retenção como "dica" para integrar informações e utilizá-las em momentos posteriores. Após um mês de experiências, os bebês do GI evocaram informações definitivas já na retenção, não modificando seu desempenho no pós-retenção. A dica não foi efetiva para auxiliar os bebês que não lembraram na tarefa em reavivar as lembranças e integrá-las a novas informações.

Dentre as tarefas, observou-se que aquela de retirar a cobertura de um brinquedo escondido parecia ser fácil para os bebês. A literatura sugere que os bebês tornam-se aptos a realizar esta tarefa aos cinco meses e esta ação estabiliza-se entre oito a dez meses ${ }^{(17)}$. De fato, essa foi a tarefa mais lembrada na retenção por ambos os grupos, embora os bebês do GI demonstrassem desempenho superior. O bebê, ao ver o pano encobrindo algo, rapidamente retirava-o do brinquedo. Em alguns momentos, apenas uma das mãos era utilizada e, em outros, as duas mãos eram empregadas para realizar a atividade. Em estudo prévio, Fagard e Pazé(16) $r e l a t a r a m$ comportamento semelhante, sugerindo que esta tarefa é mais fácil de ser aprendida do que a de retirar o brinquedo de uma caixa, pois o bebê pode usar estratégias uni e bimanuais. A mudança positiva da avaliação inicial para a retenção na tarefa de descobrir o brinquedo só foi observada no GI, indicando que o programa de intervenção pode ter criado condições para o estabelecimento de período sensível à aprendizagem mais longo, conduzindo à aprendizagem diferenciada no $\mathrm{GI}^{(7)}$. Se somente critérios de maturação fossem determinantes na aprendizagem, os resultados em ambos os grupos seriam semelhantes. Destaca-se que os bebês que não reconheceram a tarefa na retenção, não obtiveram respostas positivas no período pós-retenção, tanto no GI como no GC. O GI, após um mês de experiências, provavelmente evocou informações definitivas já na retenção, não modificando seu desempenho depois de três dias.

Os resultados sugerem que a tarefa de retirar quatro pequenos brinquedos de um tubo de papelão unidos por um barbante foi a mais complexa para os bebês. O sucesso para tal atividade, com a retirada de todos os brinquedos de uma só vez, não foi atingido por nenhum bebê no primeiro dia. Nesse mesmo dia, foi-lhes ensinada a tarefa até que o bebê a realizasse sozinho. Quando foi apresentada a tarefa para o bebê um mês depois, na retenção, foi como se eles a estivessem realizando pela primeira vez, o que não aconteceu com as outras tarefas. No entanto, após a "dica", ou seja, a prática novamente na retenção com o objetivo de recuperar a memória perdida, os bebês conseguiram realizar as tarefas no período pós-retenção, seguindo tendência observada na literatura $^{(9)}$. A frequência significativamente maior em bebês do GI que realizaram a tarefa no período pós-retenção sugere uma aprendizagem superior facilitada pelo processo interventivo.

Em relação à idade, os resultados da presente pesquisa se assemelham em parte com os de estudos prévios ${ }^{(9)}$ em relação à superioridade de bebês mais velhos (oito e nove meses) de lembrarem eventos passados, quando comparados aos mais jovens (seis e sete meses). Todos os bebês mais velhos reconheceram melhor os eventos do que os mais jovens; no entanto, os bebês mais velhos do GI demonstraram capacidade aumentada de evocar informação em relação aos mais jovens, comparados ao GC. É interessante ainda observar que os bebês mais velhos do GI apresentaram sequência progressiva na reativação de informações, fator não observado nos bebês mais velhos do GC. Uma possível explicação para esse fato reside, talvez, no fechamento precoce das "Janelas do Tempo" no GC e a permanência delas abertas no GI, em decorrência da efetiva exposição dos bebês a experiências que guiaram o aprendizado ${ }^{(7)}$.

Portanto, concluindo, este estudo sugere que bebês do GI demonstraram desempenho superior no teste de retenção, comparados aos seus pares do GC. Bebês do GI mostraram também, de maneira geral, capacidade superior de reativar a memória na retenção, quando comparado ao desempenho no primeiro contato. Bebês do GI e do GC, que não reconheceram as tarefas na retenção, não demonstraram capacidade de evocar essa informação depois de três dias, em consequência da reativação de memória propiciada pela "dica" da própria retenção, com exceção de uma tarefa. Bebês mais velhos (oito a nove meses) do GI demonstraram capacidade de evocar informações, na retenção, significativamente superior do que os mais novos. Acredita-se, assim, que os efeitos de programas interventivos prolongados ampliem os conhecimentos básicos do bebê, o que contribuiria para o seu aprendizado ${ }^{(7)}$. Um ambiente rico em experiências desafia as capacidades do bebê, potencializa o desenvolvimento e gera aprendizagem. Sugere-se, para os próximos estudos, verificar como as características familiares dos bebês e das pessoas que com eles convivem, bem como as características do seu meio, podem influenciar o processo de aprendizagem. 


\section{Referências bibliográficas}

1. Thelen E. Treadmill-elicited stepping in seven-month-old infants. Child Dev 1986;57:1498-506.

2. Clark JE, Whitall J. What is motor development? The lessons of history. Quest 1989;41:183-202.

3. Kim W, Gabbard C, Buchanan JJ, Ryu YU. Right-handers' reaching in contralateral hemispace: a kinematic observation. J Mot Behav 2007;39: 451-6.

4. Hsu VC, Rovee-Collier C. Memory reactivation in the second year of life. Infant Behav Dev 2006;29:91-107.

5. Gonzalez CL, Whishaw IQ, Kolb B. Complete sparing of spatial learning following posterior and posterior plus anterior cingulate cortex lesions at 10 days of age in the rat. Neuroscience 2003;122: 563-71.

6. Izquierdo I, Bevilaqua LR, Rossato JI, Bonini JS, Medina JH, Cammarota M. Different molecular cascades in different sites of the brain control memory consolidation. Trends Neurosci 2006;29:496-505.

7. Rovee-Collier C. Time windows in cognitive development. Dev Psychobiol 1995;31:147-69.

8. Adalbjornsson $\mathrm{C}$. The effects of an interactive tracking skill intervention on infant's motor and cognitive skills [tese de doutorado]. Auburn: Auburn University Press; 2001.

9. Oliveira MGM, Bueno OF. Neuropsicologia da memória humana. Psicol USP 1993;4:117-38.

10. Almeida CS, Valentini NC, Lemos CXG. A influência de um programa de intervenção motora no desenvolvimento de bebês no terceiro trimestre de vida em creches para população de baixa renda. Temas Desenvolv 2005; $14: 40-8$.

11. Valentini NC, Rudisill M. Effectiveness of an inclusive mastery climate intervention on the motor skill development of children. APAQ 2004;21:330-47.

12. Rech DM. Influências de um programa de educação motora com três diferentes abordagens interventivas no desempenho motor de crianças nascidas prétermo [tese de mestrado]. Porto Alegre (RS): Universidade Federal do Rio Grande do Sul; 2005.

13. Freitas SN. Orientações a pais e professores de alunos com altas habilidades. Rev Bras Educ Espec 2007;13:147-8.

14. Associação Brasileira de Empresas de Pesquisa [homepage on the Internet] Critério de Classificação Econômica Brasil [cited 2005 Mar 10]. Available from: http://www.abep.org/codigosguias/ABEP_CCEB_2003.pdf.

15. Arns U. Que fazemos com nossas crianças? Um estudo do atendimento das crianças de 0-3 anos nas creches públicas de Cruz Alta [tese de mestrado]. ljuí (RS): Unijuí; 1998.

16. Fagard J, Pezeacute A. Age changes in interlimb coupling and the development of bimanual coordination. J Mot Behav 1997;29:199-208.

17. Pinto EB, Vilanova LC, Vieira RM. O desenvolvimento do comportamento da criança no primeiro ano de vida: padronização de uma escala para a avaliação e o acompanhamento. São Paulo: Casa do Psicólogo; 1997.

18. Case-Smith J, Bigsby R, Clutter J. Perceptual-motor coupling in the development of grasp. Am J Occup Ther. 1998;52:102-10.

19. Campbell SK, Linden DW, Palisano RJ. Physical therapy for children. Philadelphia: Saunders; 2000. 